\title{
INFLUENCE OF ALLOYING ELEMENTS IN ZINC MELTS ON THE STRUCTURE OF LAYERS OBTAINED BY GALVANIZING
}

\author{
Tamara RADU, Florentina POTECAȘU \\ "Dunarea de Jos" University of Galati, Romania \\ e-mail: tradu@ugal.ro
}

\begin{abstract}
Zinc melts has been alloyed, in various proportions and combinations, with $\mathrm{Bi}, \mathrm{Sn}, \mathrm{Ni}, \mathrm{Pb}$. Depending on the characteristics of the alloying elements, the alloying technology of the zinc bath was established. To determine the degree of homogenization of the melt, samples were taken for metallographic analyses and chemical composition. In zinc alloyed melts were coated steel strips with low carbon. The layers obtained were analyzed in cross-section to determine the influence of the alloying elements on the Zn-Fe alloys from the support/zinc interface and on the thickness and structure of the phase $\eta$ (zinc). The chemical composition was determined by X-ray fluorescence and microstructure analysis by optical microscopy.
\end{abstract}

KEYWORDS: coating layer, optical microscopy, X-ray fluorescence, Zn-Sn$\mathrm{Pb}-\mathrm{Bi}-\mathrm{Ni}$ alloy, galvanizing

\section{Introduction}

Hot dip galvanizing technology is widely applied for the corrosion protection of steel parts so that half of the world's zinc production is used for this purpose [1]. Classical hot dip galvanizing has seen many improvements over time. Most of them aimed at increasing the corrosion resistance of the layer, changes in the melt characteristics (fluidity, superficial tension, etc.) and reducing the amount of dross. In order to achieve these objectives, a modification of the composition of the zinc bath by alloying with various elements was applied in various combinations, namely: Al [2, 3], Sn [4], Mg [5], Bi $[6,7]$, Ni [8-10]. Aluminum is the most widely used and studied alloying element of zinc melt having favorable effects both on the characteristics of the layer and on the zinc melt [11]. At present, galvanizing in alloys $\mathrm{Zn}-\mathrm{Mg}-\mathrm{Al}$ is being investigated with significant improvements in technology and product [12-14].

Bismuth is an expensive metal but can replace lead in galvanizing baths with the same effect in increasing fluidity and reducing surface tension to much lower contents and is not toxic.

Tin increases corrosion resistance of zinc layers and nickel increases melt fluidity and corrosion resistance [4, 9]. The paper analyses the influence of some of these alloying elements on the structure of the obtained layers. Several types of zinc alloys and alloying elements $\mathrm{Bi}, \mathrm{Ni}, \mathrm{Sn}, \mathrm{Pb}$ have been studied in various combinations and concentrations.

\section{Experimental conditions}

In the pure zinc melt (Table 1) alloys were introduced in different combinations, $\mathrm{Bi}, \mathrm{Sn}, \mathrm{Ni}$ and $\mathrm{Pb}$. The chemical composition of the zinc coatings studied is presented in Table 2.

Table 1. Chemical composition of zinc used in experiments, in \%

\begin{tabular}{|c|c|c|c|c|c|c|}
\hline $\mathbf{Z n}$ & $\mathbf{P b}$ & $\mathbf{C u}$ & $\mathbf{F e}$ & $\mathbf{S n}$ & $\mathbf{A l}$ & $\mathbf{C d}$ \\
\hline 99.996 & 0.0014 & 0.0004 & 0.0005 & 0.0005 & 0.0005 & 0.0004 \\
\hline
\end{tabular}

The alloying elements were gradually introduced into the zinc bath taking account their physical characteristics (Table 3). As can be seen from Table 3, $\mathrm{Bi}, \mathrm{Sn}$ and $\mathrm{Pb}$ have physical 
characteristics close to that of zinc and were introduced into the galvanizing bath at $450{ }^{\circ} \mathrm{C}$ in the form of a pure metal crushed and preheated at $200{ }^{\circ} \mathrm{C}$. Nickel has a much higher melting temperature than zinc, and $\mathrm{Zn}-\mathrm{Ni}$ pre-alloyed with $2 \% \mathrm{Ni}$, finely ground and preheated at $200{ }^{\circ} \mathrm{C}$, was used to alloy the zinc bath. It was introduced into zinc bath at $600{ }^{\circ} \mathrm{C}$. In all cases, mechanical homogenization was applied. After homogenization, samples were taken which were analyzed with an X-ray spectrometer type Invov-X System.

Table 2. Chemical composition of alloys used in experiments

\begin{tabular}{|c|c|c|c|c|c|}
\hline \multirow{2}{*}{ Alloy } & \multicolumn{5}{|c|}{ Alloying elements, [\%] } \\
\cline { 2 - 6 } & $\mathrm{Pb}$ & $\mathrm{Bi}$ & $\mathrm{Sn}$ & $\mathrm{Ni}$ & $\mathrm{Zn}$ \\
\hline $\mathrm{Zn}-\mathrm{Bi}$ & 0 & 0.36 & 0 & 0 & rest \\
\hline $\mathrm{Zn}-\mathrm{Bi}-\mathrm{Sn}$ & 0 & 0.35 & 3.50 & 0 & rest \\
\hline $\mathrm{Zn}-\mathrm{Bi}-\mathrm{Sn}-\mathrm{Ni}$ & 0 & 0.41 & 3.49 & 0.17 & rest \\
\hline $\mathrm{Zn}-\mathrm{Pb}-\mathrm{Bi}-\mathrm{Sn}-\mathrm{Ni}$ & 0.72 & 0.41 & 3.88 & 0.16 & rest \\
\hline
\end{tabular}

Table 3. Physical characteristics of zinc and alloying elements used

\begin{tabular}{|c|c|c|c|c|}
\hline \multirow{2}{*}{ Element } & \multicolumn{4}{|c|}{ Physical characteristics } \\
\cline { 2 - 5 } & $\begin{array}{c}\text { Density } \\
{\left[\mathbf{k g} / \mathbf{d m}^{\mathbf{3}} \mathbf{x 1 0} \mathbf{~}^{\mathbf{3}}\right]} \\
\mathbf{a t ~ 2 0}^{\mathbf{0}} \mathbf{C}\end{array}$ & $\begin{array}{c}\text { Melting point } \\
\mathbf{0}\end{array}$ & $\begin{array}{c}\text { Boiling point } \\
\mathbf{0} \mathbf{C}\end{array}$ & $\begin{array}{c}\text { Latent heat } \\
{[\mathbf{C a l} / \mathbf{g}]}\end{array}$ \\
\hline $\mathrm{Zn}$ & 7.13 & 419.5 & 907 & 27.3 \\
\hline $\mathrm{Bi}$ & 9.8 & 271 & 1440 & - \\
\hline $\mathrm{Sn}$ & 7.3 & 232 & 2590 & 73.96 \\
\hline $\mathrm{Ni}$ & 8.9 & 1455 & 3000 & 5.75 \\
\hline $\mathrm{Pb}$ & 11.34 & 327.4 & 1750 & \\
\hline
\end{tabular}

Table 4. Chemical composition of strip steel (support) in [\%]

\begin{tabular}{|c|c|c|c|c|c|c|c|c|}
\hline $\mathbf{C}$ & $\mathbf{S i}$ & $\mathbf{M n}$ & $\mathbf{P}$ & $\mathbf{S}$ & $\mathbf{A l}$ & $\mathbf{C u}$ & $\mathbf{N i}$ & $\mathbf{C r}$ \\
\hline 0.040 & 0.023 & 0.210 & 0.010 & 0.012 & 0.039 & 0.015 & 0.020 & 0.020 \\
\hline
\end{tabular}

The chemical composition, of covered steel strip is shown in Table 4.

The galvanizing was done at a temperature of $450{ }^{\circ} \mathrm{C}$ with a 10 second immersion time. The obtained layers were analyzed in cross-section by optical microscopy on an Olympus-type microscope.

\section{Results and discussions}

The metallographic analysis of the microstructure of the coating layer, obtained in alloyed zinc, shows significant changes compared to the microstructure of pure zinc layers (Fig. 1).

The influence of the alloying elements is manifested both in the structure and size of the alloy layer, which is formed at the interface with the support steel, following the reactions between iron and zinc, as well as in the structure of the resulting zone by the entrainment of the bath melt and located over the Zn-Fe alloys layer.
The two areas are distinct both on attacked and un-attacked samples. On the attacked sample (Fig. 1), the layer of $\mathrm{Zn}$-Fe alloys (formed of phases $\Gamma, \delta, \zeta$ ) appears darker than the zinc sheet in the layer surface (phase $\eta$ ). On non-attack samples the intermetallic compounds white bright are observed.

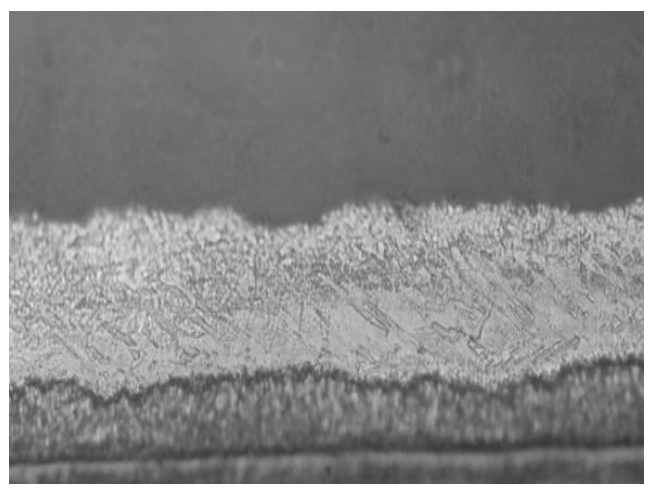

Fig. 1. The layer microstructure obtained in pure zinc, $x 200$ 


\section{THE ANNALS OF “DUNAREA DE JOS” UNIVERSITY OF GALATI \\ FASCICLE IX. METALLURGY AND MATERIALS SCIENCE \\ No. 4 - 2018, ISSN 2668-4748; e-ISSN 2668-4756 \\ Article DOI: https://doi.org/10.35219/mms.2018.4.02}

Alloying of the zinc with $0.36 \% \mathrm{Bi}$. Bismuth is added to the zinc bath to increase the melt fluidity and it can replace the lead, considered toxic to the environment. Microstructural analysis of the layer obtained in this alloy (Figures $2 \mathrm{a}$ and $\mathrm{b}$ ) shows a decrease in the phase layer $\eta$ due to the increase in melt fluidity. The $\mathrm{Zn}-\mathrm{Fe}$ alloy layer does not change significantly from pure zinc coating. However, there is a diminution of this when bismuth particles

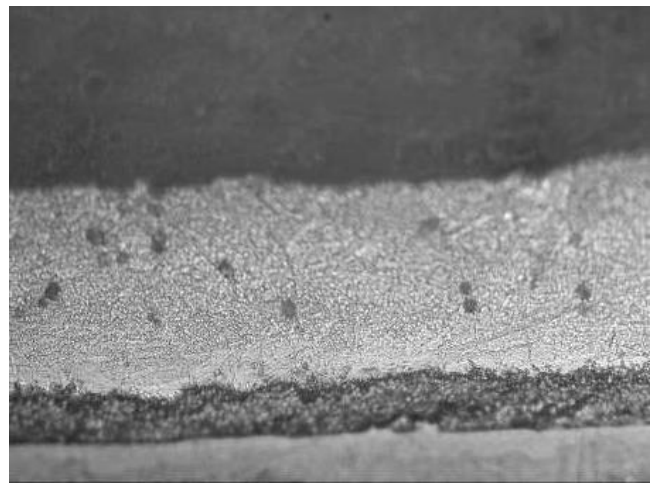

a) with attack mechanically block Zn-Fe layer growth (Fig. 3). Since bismuth and zinc are insoluble in the solid phase, separation of bismuth crystals is observed in the $\eta$ phase (zinc) layer. On rapid cooling they are dispersed homogeneously (Fig. 2b) and during slow cooling they clump to the surface (Fig. 3).

Separation of bismuth crystals in the zinc matrix was also revealed in the microstructural analysis of samples taken from the bath with Zn-Bi alloy (Fig. 4).

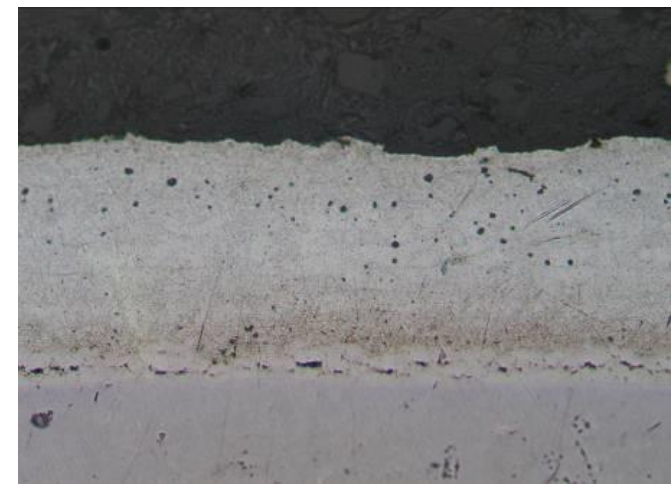

b) non attack

$\mathrm{x} 800$

Fig. 2. Microstructure of coating layer obtained by micro alloying with $0.36 \% \mathrm{Bi}$

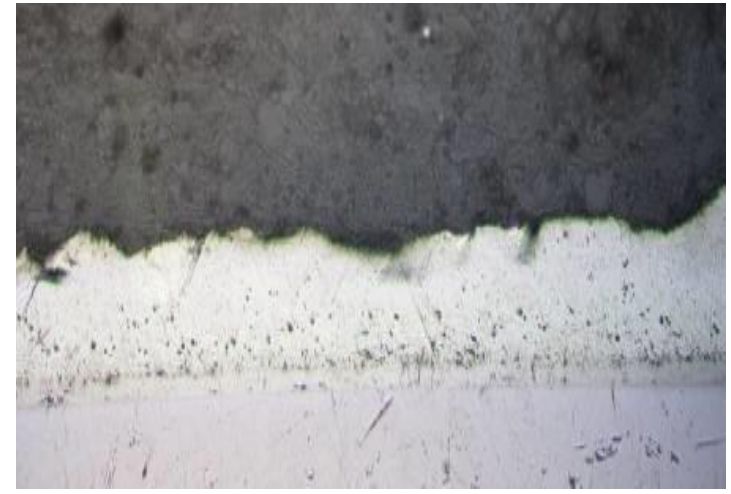

Fig. 3. Agglomeration of the bismuth crystals at the growth front of Zn-Fe phase, x400, non-attack

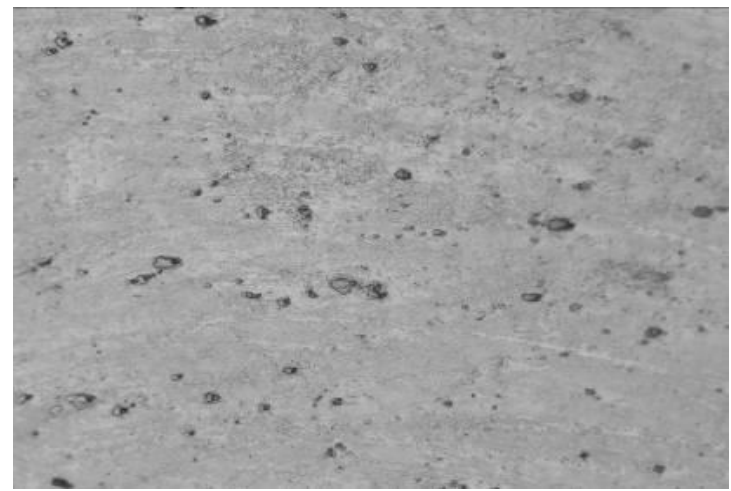

Fig. 4. Microstructure of Zn-Bi alloy, x400 
Microstructure of $\mathrm{Zn}-\mathrm{Sn}-\mathrm{Bi}$ layers. The Tin is added to the zinc bath in order to increase the corrosion resistance of the layer. Alloying with tin increases the corrosion resistance of the coating but, at the same time, leads to an increase in layer thickness (Fig. $5 \mathrm{a}$ and b). For this reason, tin is not

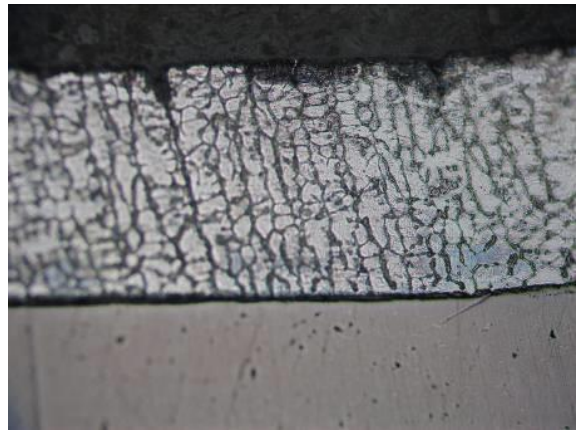

a) with attack added alone to the zinc bath and it is accompanied by a melt fluidity enhancing element such as lead or bismuth. Tin, in a concentration of over $2.5 \%$, acts on the layer of $\mathrm{Zn}-\mathrm{Fe}$ alloys to reduce it by forming a mechanical barrier between the intermetallic and zinc phase (Fig. 5b).

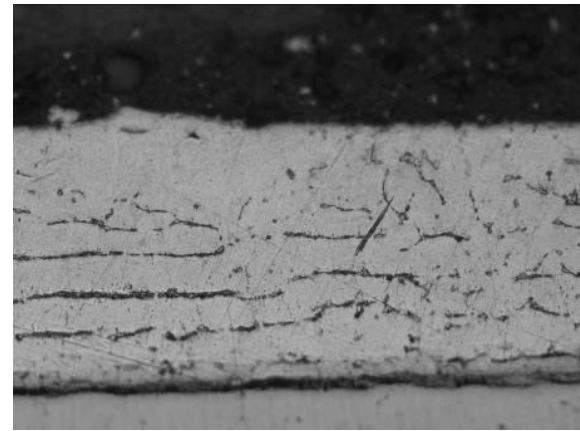

b) non attack

Fig. 5. The microstructure of the coating layer obtained in Zn-Bi-Sn alloy

Fig. 6 shows the microscopic appearance of the $\mathrm{Zn}-\mathrm{Sn}-\mathrm{Bi}$ alloy. Tin and bismuth are elements insoluble in zinc and they separate as crystals in the zinc mass or at grain boundary.

Melt alloying with Ni. Nickel increases the fluidity of the zinc melt and increases the corrosion resistance of the coating. In the structure of the protective layers obtained in alloyed baths simultaneously with nickel-tin-bismuth (Fig. 7), it is observed the effect on the iron-zinc alloy layer, which is drastically reduced. The effect is cumulative of nickel and tin, the bismuth acting on the thickness of the layer, in the sense of reducing it, by increasing the melt fluidity and decreasing the superficial tension.

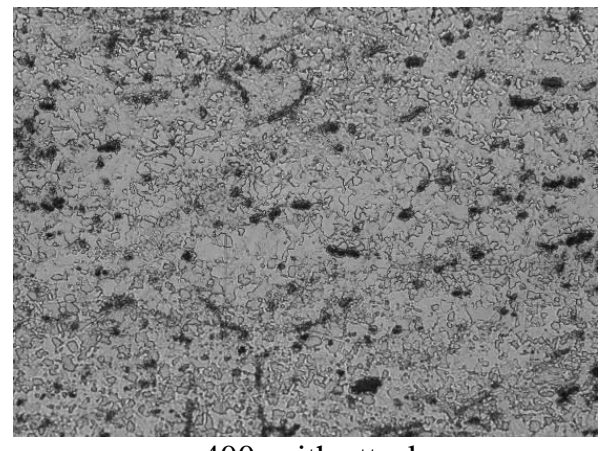

x400, with attack

\section{Fig. 6. Microstructure of the Zn-Sn-Bi alloy}

The formation of many compounds between nickel and zinc and between nickel and the other micro alloying elements ( $\mathrm{Sn}$ and $\mathrm{Bi}$ ) leads to the obtaining of a composite structure for $\mathrm{Zn}-\mathrm{Ni}-\mathrm{Sn}-\mathrm{Bi}$ alloy with intermetallic compounds dispersed in the zinc matrix (Fig. 8).

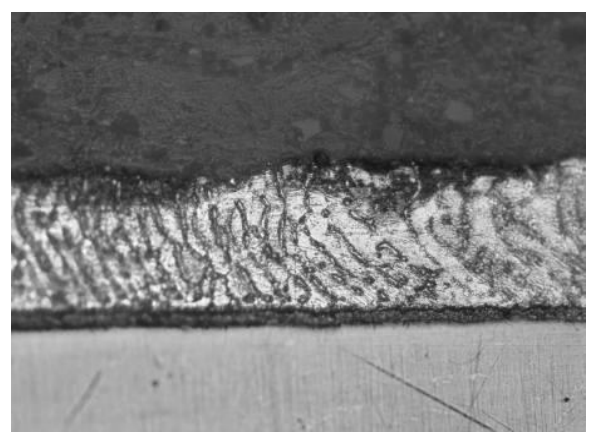

x400, with attack

Fig. 7. The microstructure of the coating layer obtained in Zn-Sn-Bi-Ni alloy

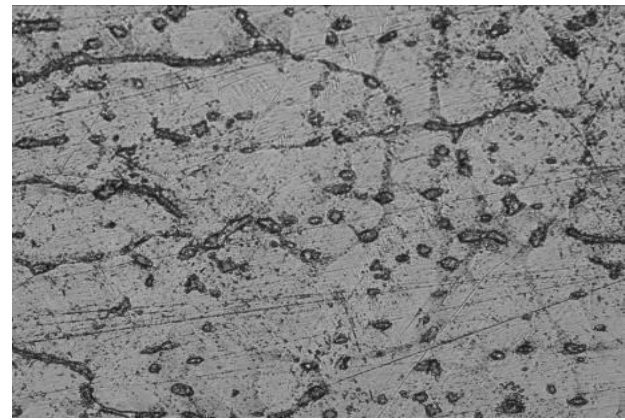

Fig. 8. Microstructure of the Zn-Sn-Bi-Ni alloy, $x 400$, with attack

At the simultaneous alloying with lead and bismuth we obtain finer and uniform layers with the same aspect of the microstructure (Fig. 9 a and b) as the layer obtained in $\mathrm{Zn}-\mathrm{Sn}-\mathrm{Bi}-\mathrm{Ni}$ alloy. The presence near bismuth of an important percentage of lead 
increases significantly the fluidity of the melt, and the amount of zinc (phase $\eta$ ) entrained on the sheet is smaller. Thus, a large amount of precipitates is formed in the zinc matrix and coalescing phenomena are manifested.

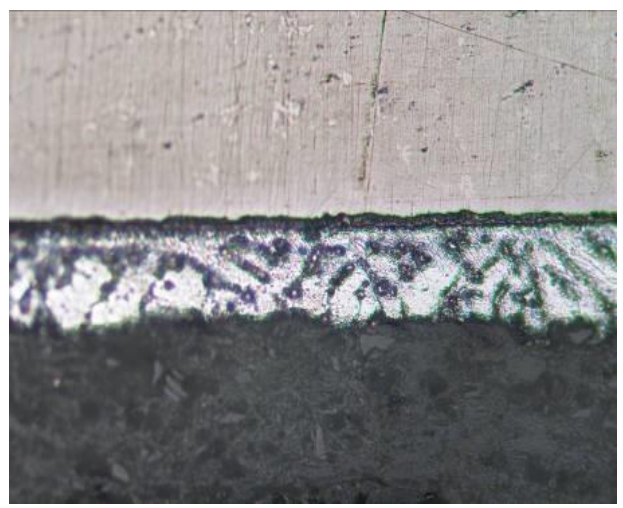

a) $\mathrm{x} 400$ with attack

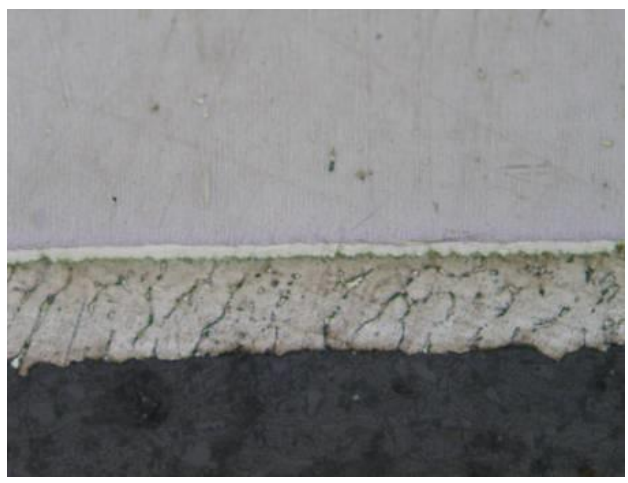

b) $\mathrm{x} 400$, non-attack

Fig. 9. The microstructure of the coating layer obtained in $\mathrm{Zn}-\mathrm{Sn}-\mathrm{Pb}-\mathrm{Bi}$-Ni alloy (intermetallic compounds and lead crystals in dendrite zinc matrix)

\section{Conclusions}

Microstructural analysis of the layer obtained in $\mathrm{Zn}$-Bi alloy, with $0.36 \% \mathrm{Bi}$, shows a decrease in the phase layer $\eta$ due to the increase in melt fluidity in presence of $\mathrm{Bi}$. The $\mathrm{Zn}-\mathrm{Fe}$ alloy layer does not change significantly from pure zinc coating.

Tin leads to an increase in layer thickness of the coating and for this reason, tin is not added alone to the zinc bath and it is accompanied by a melt fluidity enhancing element such as lead or bismuth. In a concentration of over $2.5 \%$ tin acts on the layer of
$\mathrm{Zn}-\mathrm{Fe}$ alloys to reduce it by forming a mechanical barrier between the intermetallic and zinc phase

In the structure of the protective layers obtained in $\mathrm{Zn}-\mathrm{Sn}-\mathrm{Bi}-\mathrm{Ni}$ alloy is observed the effect on the iron-zinc alloy layer, which is drastically reduced. The effect is cumulative of nickel and tin, the bismuth acting on the thickness of the layer, in the sense of reducing it.

At the simultaneous alloying with lead and bismuth we obtain finer and uniform layers with the same aspect of the microstructure (Fig. 9 a and b) as the layer obtained in $\mathrm{Zn}-\mathrm{Sn}-\mathrm{Bi}-\mathrm{Ni}$ alloy but the amount of zinc (phase $\eta$ ) entrained on the sheet is smaller because the presence simultaneous of bismuth and lead increases significantly the fluidity of the melt.

\section{References}

[1]. ***, http://www.vmzinc-us.com.

[2]. Ball J., Poos A., Hot-dip galvanized product for the automotive industries, Revue de Metallurgy, no. 6, p. 570, 2002.

[3]. Radu T., Balint L., Balint S., The alloys Zn-Al used for protection of sheet steel, Analele Universităţii "Dunărea de Jos" din Galaţi, Fascicula IX, Metalurgie şi Ştiinţa Materialelor, p. 5460, ISSN 1453-083 X, 2003.

[4]. ***, https://www.researchgate.net/publication/222157292.

[5]. Shukla S. K., Deepa M., Santos h Kumar, Effect of $M g$ Addition (in Zinc Bath) on Galvanized Sheet quality, International Journal of Materials Engineering, 2(6), p. 105-111, DOI: 10.5923/j.ijme.20120206.05, 2012.

[6]. Tamara Radu, Florentina Potecasu, Maria Vlad, Research on obtaining and characterization of zinc micro-alloyed with bismuth coatings, Metalurgia International no. 1, ISSN 1582-2214, p. 44-48, 2011.

[7]. Pistofidis N., Vourlias G., Pavlidou E., Stergioudis G., Effect of Ti, Ni and Bi addition to the corrosion resistance of $\mathrm{Zn}$ hot-dip galvanized coatings, Journal of optoelectronics and advanced materials, vol. 9, no. 6, p. 1653, 2007.

[8]. Reumont G., Perrot P., Foct J., Thermodynamic study of the galvanizing process in a $\mathrm{Zn}-0,1 \% \mathrm{Ni}$ bath, Journal of Materials Science 33, p. 4759-4768, 1998.

[9]. Lewis G. P., Pederson J., Optimizing the Ni-Zn process for hot dip galvanizing, Cominco LTD., 1998.

[10]. Alonso C., Sanchez J., Fullea J., Andrade C., Tierra P., Bernal M., The addition of nickel to improve the corrosion resistance of galvanized reinforcement, 1995.

[11]. ***, https://galvanizeit.org/uploads/publications.

[12]. Caizhen Yao, See Leng Tay, Ji Hyun Yang, Tianping Zhu, Wei Gao, Hot Dipped $\mathrm{Zn}-\mathrm{Al}-\mathrm{Mg}-\mathrm{Cu}$ Coating with Improved Mechanical and Anticorrosion Properties, Int. J. Electrochem. Sci., 9, p. 7083-7096, 2014.

[13]. Min-Suk Oh, Sang-Heon Kim, Su-Young Kim, Tae-Chul Kim and Jong-Sang Kim, Effect of coating composition on microstructural properties and corrosion resistance of $\mathrm{Zn}-\mathrm{Mg}-\mathrm{Al}$ alloy coated steel sheets, METAL 2014, May $21^{\text {st }}-23^{\text {rd }}$, Brno, Czech Republic, EU, 2014.

[14]. Commenda C., Pühringer J., Microstructural characterization and quantification of $\mathrm{Zn}-\mathrm{Al}-\mathrm{Mg}$ surface coatings, Materials Characterization, vol. 61, issue 10, p. 943-951, 2010. 